\title{
MODEL FOR EVALUATING ADDITIVE MANUFACTURING FEASIBILITY IN END-USE PRODUCTION
}

\author{
Ahtiluoto, Matti (1); Ellman, Asko Uolevi (2); Coatanea, Eric (2) \\ 1: Enmac Ltd.; 2: Tampere University of Technology
}

\begin{abstract}
In practical design work, a designer needs to consider the feasibility of a part for a manufacturing using additive manufacturing (AM) instead of conventional manufacturing (CM) technology. Traditionally and by default parts are assumed to be manufactured using CM and using AM as an alternative need to be justified. AM is currently often a more expensive manufacturing method than CM, but its employment can be justified due to number of reasons: improved part features, faster manufacturing time and lower cost. Improved part features means usually reduced mass or complex shape. However, in low volume production lower manufacturing time and lower part cost may rise to the most important characteristics.

In this paper, we present a practical feasibility model, which analyses the added value of using AM for manufacturing. The approach is demonstrated in the paper on four specific parts. They represent real industrial design tasks that are ordered from an engineering office company. These parts were manufactured by Selective Laser Meting (SLM) technology and the original design done for conventional manufacturing is also presented and used for comparison purpose.
\end{abstract}

Keywords: Design for Additive Manufacturing (DfAM), Decision making, 3D printing, Additive Manufacturing

Contact:

Ellman, Asko Uolevi

Tampere University of Technology

Mechanical Engineering and Industrial Systems

Finland

asko.ellman@tut.fi

Cite this article: Ahtiluoto, M., Ellman, A.U., Coatanea, E. (2019) 'Model for Evaluating Additive Manufacturing Feasibility in End-Use Production', in Proceedings of the 22nd International Conference on Engineering Design (ICED19), Delft, The Netherlands, 5-8 August 2019. DOI:10.1017/dsi.2019.84 


\section{INTRODUCTION}

Additive Manufacturing (AM) also known as 3D-Printing has begun to evolve from rapid prototyping to direct digital manufacturing for end-use components (Lindemann et al. 2015, Gao et al., 2015). AM is recently a topic of great excitement both in academia as well as in manufacturing business due to the unique capabilities and features of these fabrication processes. AM processes add successively material and energy to a domain, in order to generate a pre-specified 3D geometry. Compared to Conventional Manufacturing (CM) technologies, AM provides great flexibility in introducing geometric features across multiple scales that would be difficult or impossible to realize using conventional manufacturing means. As a result, the use of AM for low volume or customized manufacturing applications has become widespread (Booth et al., 2017).

AM processes have reached their industrial maturity in large-scale production and they are being adopted at ever-increasing pace in the industry, despite challenges considering part qualification especially in aerospace and medical sectors. Commercial success stories in the field of AM have been increasing rapidly in the past few years (Wohlers, 2018). Today, the variety of additive manufacturing technologies and available materials have opened new possibilities and tools for designers. However, today designers are challenged with lack of understanding of AM capabilities, process-related constraints, and their effect to final product (Simpson and Williams, 2017). Therefore, design rules are acknowledged necessary for supporting the decision-making in AM, which technology should the designer use for the part manufacturing and what needs to be considered in design. There are several studies on this topic as there are also several manufacturing processes for AM (Adam and Zimmer, 2014, Stankovic et al., 2015, Gorguluarslan et al., 2015, Zegard and Paulino, 2016, Robbins et al., 2016, Mani and Witherell 2017, Ranjan et al., 2017, Michopoulos et al., 2018, Panesar et al., 2018,). One interesting application of AM is manufacturing of discontinued spare parts that are no longer in available (Montero, 2018).

Advancing technology and increasing popularity has resulted in more affordable prices and 3DP (3DPrinting) services are made easily available for anybody by services such as 3D Hubs. However, despite the increased possibilities provided by AM, the lack of know-how that is required to design 3D-printed parts for industrial purposes is a major hurdle that prevents companies from capitalizing on the possibilities provided by AM (Lindemann et al., 2015, Booth et al., 2017)

In this paper, we present a practical feasibility model, which analyses the added value and suitability of using AM for manufacturing. The approach is demonstrated in the paper on four specific cases. They represent real industrial design tasks that are ordered from an engineering company. These parts were designed for Selective Laser Melting (SLM) technology. The geometry for conventional manufacturing is presented and used for comparison purpose.

\section{FEASIBILITY MODEL}

\subsection{Background and previous research}

In practical design work, a designer often needs to consider if certain part or assembly is feasible to be manufactured with AM instead of CM. Traditionally, and by default, parts are assumed to be manufactured using CM and using AM instead needs to be justified. The employment of AM can be justified due to various reasons:

- Special part features. AM enables fabrication of special features that are very expensive or even impossible to achieve with CM. For example, with lattice structures or internal cavities great weight-saving may be achieved. Optimized or complex shapes contribute to better technical functionality and performance, such as flow properties in flow channels. Possibility of using complex shapes gives more freedom to design aesthetically and ergonomically better solutions.

- Manufacturing time. AM technology is often advantageous over some traditional manufacturing processes regarding the manufacturing speed, especially with low production volumes. For example, a cast metal part may take months to be manufactured whereas in SLM, the part can be manufactured in a matter of few days and no tooling cost is required.

- Manufacturing cost. In AM enables designers to fabricate complex shapes because complexity does not affect the manufacturing cost. For this reason, complex parts may be significantly cheaper than parts with similar geometry that are manufactured by traditional subtractive or forming 
manufacturing processes. Especially with low production volume, the AM manufacturing cost is often competitive for small parts.

In order to evaluate the financial and technical feasibility of using AM for part manufacturing, engineers need a practical and predictive model enabling them to estimate cost and other AM advantages in order to justify the use of AM . Barclifit et al. (2017) have presented a CAD integrated cost estimation solution for supporting AM. Ghiasian et al. (2018) introduced a framework, which evaluate part fabrication feasibility based on geometric evaluation, build orientation/support generation and resource estimation. Our approach is based on the direct integration of expert knowledge. This is justified by the practical observation that advantage for using AM in industrial projects is due often to combined advantages obtained from the combination of part performance, part delivery time and part cost.

The relative importance of these advantages (performance, delivery time, cost) is specific to each case. In most studies, the technical part performance is emphasized, and this is the case for some design projects as well. However, depending on the situation, part performance may not be the most important factor. Sometimes the shorter delivery time provided by AM alone is a solid justification for using AM. Often manufacturing cost is the most important factor and achieved better technical properties are secondary.

\subsection{Feasibility index}

In this study, the authors introduce a feasibility index I for evaluating the feasibility of using AM for production, as shown in equation (1). The model compares AM to CM, and $\mathrm{CM}$ manufactured part performance $\mathrm{P}_{\mathrm{CM}}$ has value one, the reference level to which $\mathrm{AM}$ part performance is compared to. The equation consists of case-specific weighting factors $\mathrm{k}_{\mathrm{i}}$ for each AM advantage: part performance, manufacturing speed and part cost. The higher the index value the more suitable the part is for AM.

$$
\begin{aligned}
& I=k_{1} \frac{P_{A M}}{P_{C M}}+k_{2} \frac{T_{d C M}+T_{C M}}{T_{d A M}+T_{A M}}+k_{3} \frac{C_{d C M}+n C_{C M}}{C_{d A M}+n C_{A M}} \\
& k_{1}+k_{2}+k_{3}=1
\end{aligned}
$$

where

$\mathrm{k}_{1}=$ weighting factor for part performance $[0 \ldots 1]$

$\mathrm{k}_{2}=$ weighting factor for manufacturing speed $[0 \ldots 1]$

$\mathrm{k}_{3}=$ weighting factor for part cost $[0 \ldots 1]$

The other parameters of the equation (1) are:

$\mathrm{P}_{\mathrm{AM}}=$ Performance of AM manufactured part

$\mathrm{P}_{\mathrm{CM}}=$ Performance of CM manufactured part

$\mathrm{T}_{\mathrm{dAM}}=$ Design time for AM technology

$\mathrm{T}_{\mathrm{AM}}=$ Manufacturing time with AM technology

$\mathrm{T}_{\mathrm{dCM}}=$ Design time for CM technology

$\mathrm{T}_{\mathrm{CM}}=$ Manufacturing time with CM technology

$\mathrm{C}_{\mathrm{dCM}}=$ Design cost with CM technology

$\mathrm{C}_{\mathrm{dAM}}=$ Design cost with AM technology

$\mathrm{C}_{\mathrm{CM}}=$ Manufacturing cost of an individual part with CM technology

$\mathrm{C}_{\mathrm{AM}}=$ Manufacturing cost of an individual part with AM technology

$\mathrm{n} \quad=$ Part production volume

The weighting factors as well as the performance value $\mathrm{P}_{\mathrm{AM}}$ can be defined by design experts, for example by using a pair-wise comparison method such as the AHP (Analytic Hierarchy Process) method (Saaty, 2008). AHP method offers a way of comparing and tracking evaluations made by different experts. It could also be used as an approach to collect expert knowledge. Nevertheless, in literature it is known that high level of expertise is associated to the capability of comparing manufacturing technologies.

Exact values for some of the parameters in equation (1) may be difficult to specify, such as AM part performance. It should be noted that expertise is required for providing reasonably accurate estimates for AM part performance. Estimates made by different experts must be consistent in scale. Sometimes design and manufacturing times and cost in both AM and CM must be estimated and exact values are 
not available. However, estimates for these parameters can be given reliably based on past design experience and history data, or partly based on simulation. Experienced designers can usually estimate $\mathrm{CM}$ parameters and in the case of redesign for AM, they are known. The manufacturing time is dependent on workload of subcontractor and therefore it may vary depending on the time and situation as well.

In case of a new part, the required design work increases delivery time and part cost. Usually this increase is lower for $\mathrm{CM}$ as AM design is usually more complicated to leverage AM benefits. However, manufacturing drawing is often not necessary for AM processes. In case of redesign from $\mathrm{CM}$ to $\mathrm{AM}$ the $\mathrm{T}_{\mathrm{dCM}}$ is naturally null. In low volume production, the design cost may have a significant role in cost per part and overall feasibility. The manufacturing cost is a function of production volume $\mathrm{n}$ and $\mathrm{CM}$ part cost is more sensitive to changes in production volume.

Feasibility index value of lower than one means that the case is not suitable for AM. Feasibility index from 1,0 to 2,0 does not guarantee that AM is suitable for the case, but AM should be considered as an alternative. Feasibility index higher than 2,0 show that AM provides benefits and is advantageous.

Low weight is one of AM benefits and this can be achieved by improved, optimized design. Saving in weight is described by a mass reduction factor $\mathrm{R}$ that describes how much weight saving is achievable by use of $\mathrm{AM}$, as described in equation (2):

$$
R=\frac{m_{A M}}{m_{C M}}
$$

where

$\mathrm{m}_{\mathrm{CM}}=$ Mass of CM manufactured part

$\mathrm{m}_{\mathrm{AM}}=$ Mass of AM manufactured part

The mass reduction factor gives insight and data to designers on how much weight can be saved on certain kind of parts. History information of previous redesign cases is helpful for cost estimation as well, as with most AM technologies the manufacturing cost increases linearly as part volume increases.

\section{MODEL VERIFICATION WITH EXAMPLE CASES}

Four different example cases are analyzed in tables 1-4 using the presented feasibility model. They present different real design tasks completed by an engineering company with profound knowledge of design for AM. Tables show completed designs for AM and CM technologies, and mass and material in both cases. In addition, part production volume $\mathrm{n}$ is listed and design case is shortly introduced. The evaluation of parameters are context and time dependent. In other words, the economic context as well as the production context and machine availability at a certain moment will influence the results of the evaluation. Experts are able to recognize these changes and update the parameters accordingly. 
Table 1. Case of a nozzle design.

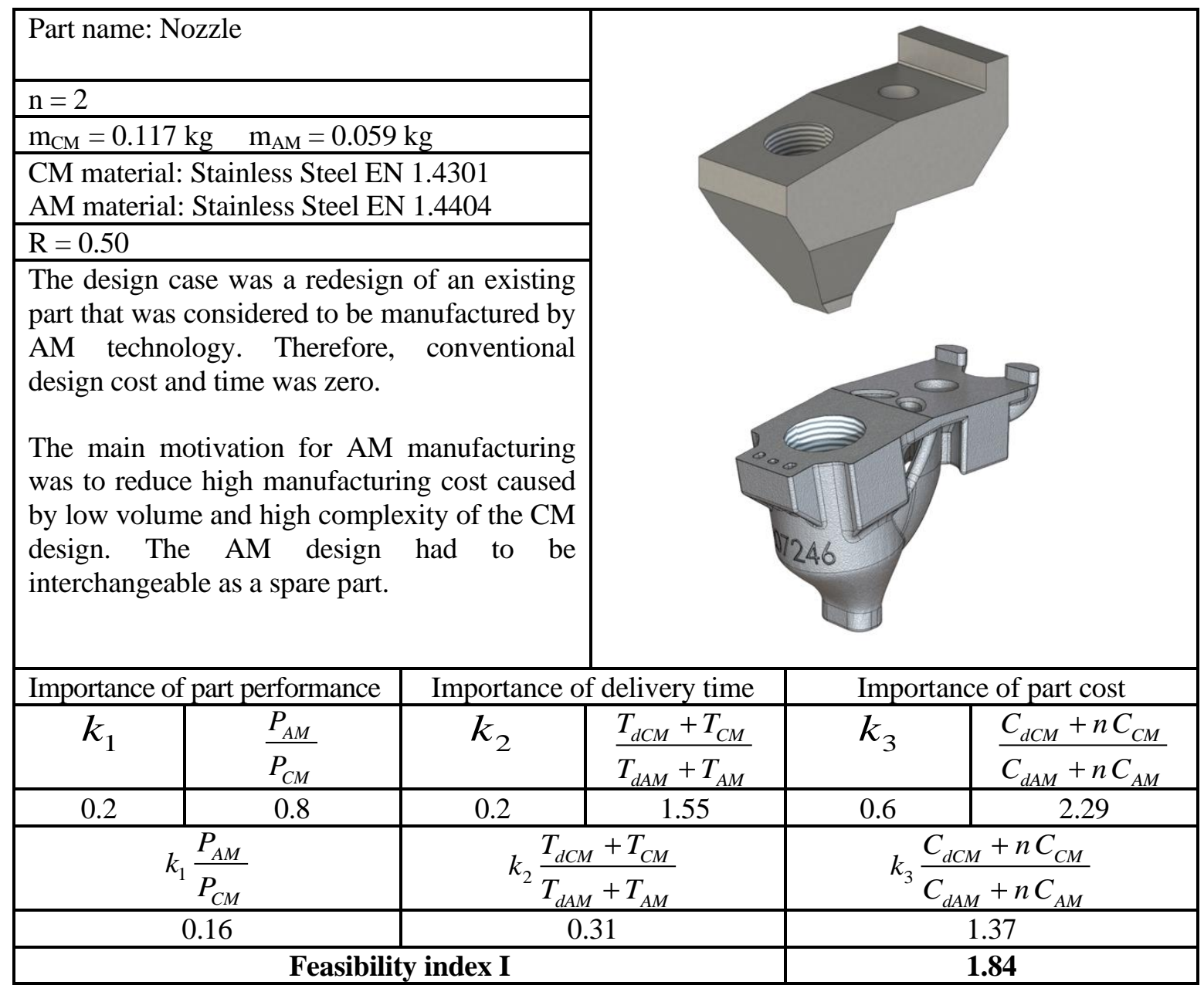

In this case (table 1) the performance of AM part was lower than with CM. This is due to lower surface quality achievable by SLM technology. However, the part was clearly cheaper and faster to manufacture with AM technology despite at production volume $n=2$. Post-process machining is necessary for fabrication of one threaded hole. Post-process machining cost is included in AM part manufacturing cost $\mathrm{C}_{\mathrm{AM}}$.

The feasibility index I is 1.84 which means that this part is sensible to be manufactured by AM. This is an example where use of AM is justified despite of lower part performance. This due to significant cost savings, which was the most important factor in this case. Cost savings were achieved despite the AM redesign cost. It is worth noting, however, that design for AM knowledge was essential in enabling cost savings as the design process was quick and efficient, and therefore redesign cost was small. 
Table 2. Case of a reflector holder design.

\begin{tabular}{|c|c|c|c|c|}
\hline \multicolumn{2}{|l|}{\begin{tabular}{|l|} 
Part name: Reflector holder \\
\end{tabular}} & & & \\
\hline \multicolumn{2}{|l|}{$\mathrm{n}=5$} & \multicolumn{3}{|c|}{$\mathrm{m}_{\mathrm{CM}}=0.30 \mathrm{~kg} \quad \mathrm{~m}_{\mathrm{AM}}=1.3 \mathrm{~kg}$} \\
\hline \multirow{2}{*}{\multicolumn{5}{|c|}{$\begin{array}{l}\text { CM material: Stainless Steel EN } 1.4404 \\
\text { AM material: Stainless Steel EN } 1.4404\end{array}$}} \\
\hline & \multicolumn{4}{|c|}{$\mathrm{R}=0.23$} \\
\hline \multirow{2}{*}{\multicolumn{5}{|c|}{$\begin{array}{l}\text { The design case was a design task of a reflector } \\
\text { holder. CM and AM geometries were designed } \\
\text { in parallel as two design variants. } \\
\text { The main motivation for AM manufacturing was } \\
\text { to achieve better part performance and lower } \\
\text { part cost. }\end{array}$}} \\
\hline & & & & \\
\hline Importance of part performance & \multicolumn{2}{|c|}{ Importance of delivery time } & \multicolumn{2}{|c|}{ Importance of part cost } \\
\hline$\frac{P_{A M}}{P_{C M}}$ & $k_{2}$ & $\frac{T_{d C M}+T_{C M}}{T_{d A M}+T_{A M}}$ & $k_{3}$ & $\frac{C_{d C M}+n C_{C M}}{C_{d A M}+n C_{A M}}$ \\
\hline 3.00 & 0.1 & 1.08 & 0.5 & 2.67 \\
\hline$k_{1} \frac{P_{A M}}{P_{C M}}$ & \multicolumn{2}{|c|}{$T_{d C M}+T_{C M}$} & $C_{d C M}+n C_{C M}$ & $\frac{+n C_{C M}}{+n C_{A M}}$ \\
\hline 1.20 & & & & 34 \\
\hline \multicolumn{3}{|c|}{ Feasibility index I } & & 65 \\
\hline
\end{tabular}

Reasons for the improved part performance by AM in this (table 2) case is better control of fixing force, more compact design which enable and better installation position and quicker assembly. Five custom parts in CM design was consolidated to two in AM design. Lower weight makes it easier to assembly and install this part. Furthermore, air flow can be better focused in this construction. The AM design includes one conventionally manufactured part, and cost of this CM part is included in AM cost.

Feasibility index of this part is 2.65 , which indicates that AM is the correct manufacturing method for this case. This part is meaningful for AM in all three aspects: it has better technical performance, shorter delivery time and it costs less than the CM part. Importance of design for AM knowledge must be highlighted, as failure to adhere with AM technology constraints may lead to build failures, costly redesign and poor part performance despite designer's intentions. Subsequently delivery time and part cost may increase substantially. 
Table 3. Case of a rack block design.

\begin{tabular}{|c|c|c|c|c|}
\hline \multicolumn{2}{|l|}{ Part name: Rack block } & & & \\
\hline \multicolumn{2}{|l|}{$\mathrm{n}=8$} & & & \\
\hline \multicolumn{5}{|l|}{$\mathrm{m}_{\mathrm{CM}}=0.317 \mathrm{~kg} \quad \mathrm{~m}_{\mathrm{AM}}=1.135 \mathrm{~kg}$} \\
\hline \multicolumn{5}{|c|}{$\begin{array}{l}\text { CM material: EN AW-7150-T77511 } \\
\text { AM material: AlSi10Mg }\end{array}$} \\
\hline \multicolumn{5}{|l|}{$\mathrm{R}=0.43$} \\
\hline \multicolumn{5}{|c|}{$\begin{array}{l}\text { The design case was a design task of customized } \\
\text { rack block. The CM and AM design variants } \\
\text { were designed in parallel, and topology } \\
\text { optimisation was used in AM design to lower } \\
\text { manufacturing cost. }\end{array}$} \\
\hline \multicolumn{5}{|c|}{$\begin{array}{l}\text { The main motivation for AM manufacturing was } \\
\text { faster delivery time. }\end{array}$} \\
\hline Importance of part performance & \multicolumn{2}{|c|}{ Importance of delivery time } & \multicolumn{2}{|c|}{ Importance of part cost } \\
\hline$\frac{P_{A M}}{P_{C M}}$ & $k_{2}$ & $\frac{T_{d C M}+T_{C M}}{T_{d A M}+T_{A M}}$ & $k_{3}$ & $\frac{C_{d C M}+n C_{C M}}{C_{d A M}+n C_{A M}}$ \\
\hline 0.8 & 0.7 & 2.18 & 0.2 & 0.46 \\
\hline$k_{1} \frac{P_{A M}}{P_{C M}}$ & \multicolumn{2}{|c|}{$\frac{T_{d C M}+T_{C M}}{{ }_{1}}$} & $C_{d C M}+n C_{C M}$ & ${ }^{\kappa_{3}} \overline{C_{d A M}+n C_{A M}}$ \\
\hline 0.08 & & & & .09 \\
\hline \multicolumn{3}{|c|}{ Feasibility index I } & & 70 \\
\hline
\end{tabular}

In this case (table 3) the performance of AM part is weaker than in CM part. This is due to slightly worse manufacturing accuracy compared to machining. In the AM part manufactured by SLM, the flatness of surfaces is not as good as in CM part.

Feasibility index of this part is 1.70 , which indicates that use of AM technology has benefits. This is due to clearly faster delivery time which compensates slightly poorer part performance and higher part cost. The case-specific weighting factors favour delivery time over the other two advantages, and therefore feasibility index suggests that AM is beneficial in this case. Again, the design capability for AM is crucial as topology optimisation must be utilized time-efficiently in order to keep delivery time short and maintain the single AM advantage this case has. 
Table 4. Case of a water manifold design.

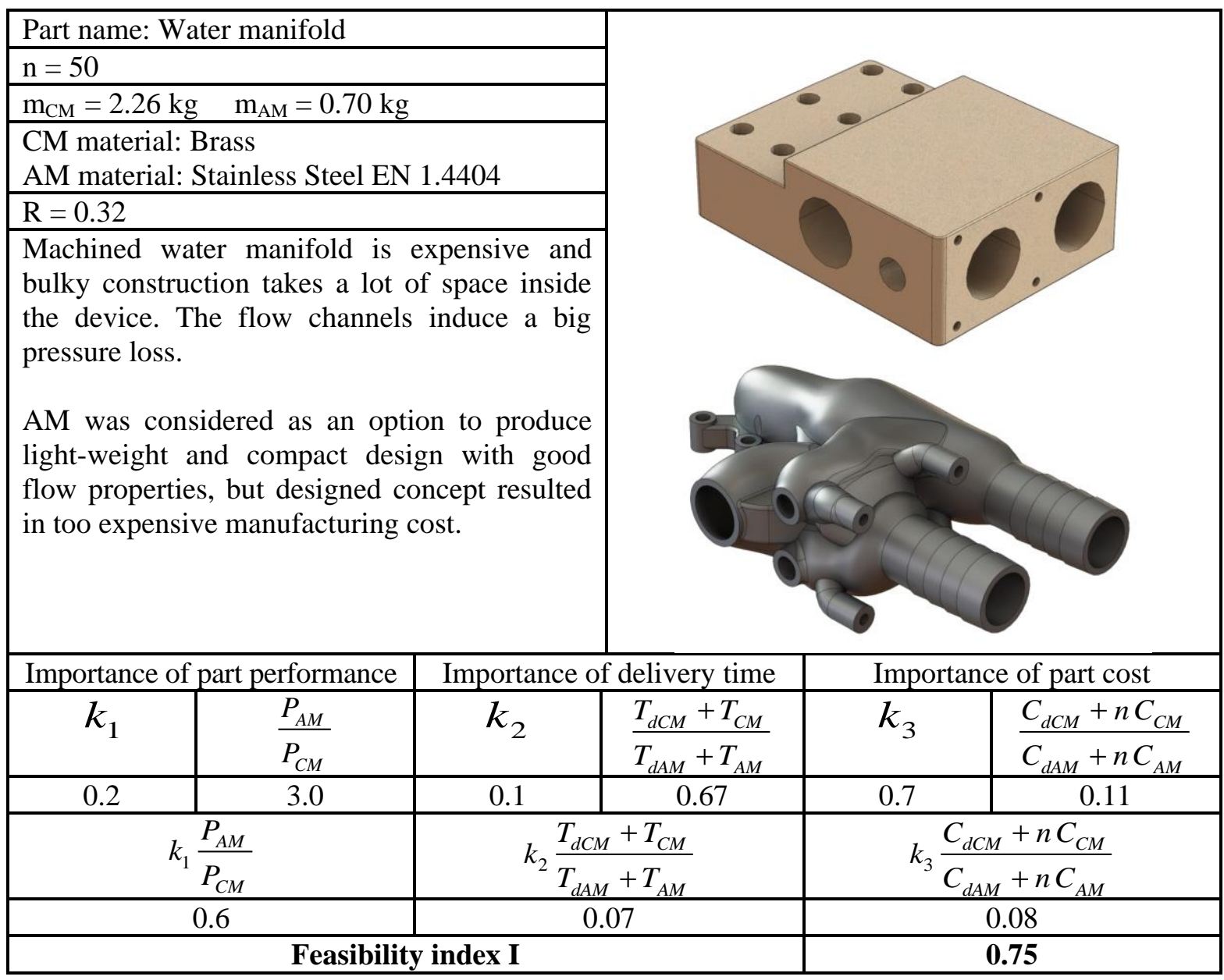

In this case (table 4), the part properties were much better with AM technology due to reduced pressure loss in flow channels. The design was compact, light-weight and had less parts due to part consolidation.

However, the feasibility index I is 0.75 which means that this part is not suitable for AM technology. This is due to much higher manufacturing cost and case-specific weighting factors do not value part performance enough to justify use of AM. The increased part performance does not affect feasibility index that much because part cost is considered much more important, and this leads to use of CM design. In addition, delivery time for AM is longer due to higher production volume.

\section{Discussion}

$\mathrm{AM}$ has been evolving rapidly over the past few years and as AM technologies together with supporting infrastructure, such as design software geared for AM developing, AM as a manufacturing method has become increasingly attracting for different businesses. For this reason, evaluating part feasibility for AM is a matter of interest and this paper offers a method for evaluating feasibility for AM from designer's point of view. Furthermore, to ensure feasibility model applicability to different cases, adjusting case-dependent weighting factors was considered necessary.

Feasibility model was used with four different parts. Three out of four cases were considered better suitable for AM than CM. Each feasibility index result is highly dependent on the used weighting factors, which are estimated by designer. Also, part performance often does not rely on testing results but on designer's estimation of part performance. Part performance is a combination of many factors, such as weight, ease of use, flow resistance, aesthetics, part consolidation, reduced assembly time and how well the part is predicted to fulfil its function. For reliable results, part performance evaluation must be done consistently. Part production volume affects to design cost so that on small volumes AM redesign cost may not be justifiable if $\mathrm{CM}$ design exists. If neither design yet exists, AM design cost may sometimes be smaller due to lack of manufacturing constraints and lack of need for manufacturing drawings. 
Also, proposed feasibility index only accounts for direct manufacturing and design cost. Manufacturing time is the time between order and delivery for a single batch of certain volume. Design time includes finalizing concept design, detail design and fabrication of potential drawings and documentation for the part to be manufactured. Future aspects such as ease of revision and updating files necessary for manufacturing are not considered in the model. Often cost-savings accumulate over the product lifetime, for example by means of part consolidation and less items to update. Manufacturing cost here is considered as the cost when parts are bought from manufacturing service provider.

Proposed feasibility index interpretation is shown in table 5.

Table 5. Feasibility index interpretation.

\begin{tabular}{|l|l|}
\hline Conclusion & Feasibility index I \\
\hline Not suitable for AM & $<1$ \\
\hline Consider both AM and CM & $1-1.5$ \\
\hline AM advantageous & $1.5-2.5$ \\
\hline Not suitable for CM & $>2.5$ \\
\hline
\end{tabular}

The presented model is aimed to be as simple as possible and including case-specific weighting factors was considered necessary to make the model applicable in justification for different business cases. Applied sum formula enables potential customization of the presented formula as terms may be added, removed or modified. Optional approaches were not considered in depth. The three advantages used here - performance, cost and time - were considered general and important factors for any business. However, use of this feasibility model is not limited to these advantages. If different advantages are used, the index interpretation should be reconsidered and calibrated with data of cases that have known properties.

For efficient use of the feasibility model it should be used as early as possible in the design phase. As soon as comparable part cost, performance and expected delivery time is known the model is usable. Ready design for both CM and AM is not a prerequisite for use of this model, although that provides best accuracy. Feasibility index is most valuable at creating an approximation on whether use of AM could be beneficial. Designers with AM knowledge are required to provide understanding of the limitations and benefits in AM when evaluating performance and AM concept design feasibility.

The used AM technology for all parts was SLM and all parts were made of metal. All conventionally manufactured parts were machined. Different AM (and CM) technologies could have been used in the feasibility calculation and this would have resulted in different feasibility index values. AM technology must be specified before evaluation because that affects part performance, delivery time and cost.

Despite main application of the model being in justification of AM in business environment and industrial use, the tool may provide to be an educational tool as well. AM is just another manufacturing method among many others and only specific parts are profitable to manufacture with AM. This feasibility model aims to provide a practical tool to understand AM applicability better.

\section{CONCLUSIONS}

Presented model provides a helpful tool for designers in evaluating part suitability for AM. This feasibility model is easily applicable by engineers in everyday business and can be utilized for variety of AM technologies, although only SLM is used in this research. This method is also customizable for specific needs by modifying estimated part properties: performance, delivery time and cost. If part feasibility is evaluated early in the design process, ideally AM method can be selected before CM design is launched and designers are able to produce technically better solutions, faster and at lower cost.

\section{REFERENCES}

Adam, G. and Zimmer, D. (2014), "Design for additive manufacturing - element transitions and aggregated structures”, CIRP Journal of Manufacturing Science and Technology, Vol. 7, pp. 20-28. http://dx.doi.org/10.1016/j.cirpj.2013.10.001.

Barclift, M., Armstrong, A., Simpson, T.W. and Joshi, S.B. (2017), “CAD-Integrated Cost Estimation and Build Orientation Optimization to Support Design for Metal Additive Manufacturing”, ASME. International 
Design Engineering Technical Conferences and Computers and Information in Engineering Conference, Vol. 2A: 43rd Design Automation Conference. https://doi.org/10.1115/DETC2017-68376.

Booth, J.W., Alperovich J, Chawla P, Ma J, Reid T.N. and Ramani K. (2017), "The design for additive manufacturing worksheet”, ASME. Jounal of Mechanical. Design, Vol. 139 No. 10, pp. 100904-100904-9. https://doi.org/10.1115/1.4037251.

Gao, W., Zhang, Y., Ramanujan, D., Ramani, K., Chen, Y., Williams, C., Wang, C., Shin, Y., Zhang, S. and Zavattieri, P. (2015), "The status, challenges, and future of additive manufacturing in engineering", Computer-Aided Design, Vol. 69. pp. 65-89. https://doi.org/10.1108/RPJ-12-2014-0179.

Ghiasian, S., Jaiswal, P., Rai, R. and Lewis, K. (2018), "From Conventional to Additive Manufacturing: Determining Component Fabrication Feasibility", ASME. International Design Engineering Technical Conferences and Computers and Information in Engineering Conference, Volume 2A: 44th Design Automation Conference. https://doi.org/10.1115/DETC2018-86238.

Gorguluarslan, R.M., Park, S-I., Rosen, D.W. and Choi, S-K. (2015), “A multilevel upscaling method for material characterization of additively manufactured part under uncertainties", ASME Journal of Mechanical Design, Vol. 137 No. 11. https://doi.org/10.1115/1.4031012.

Lindemann, C., Reiher, T., Jahnke, U. and Koch, R. (2015), “Towards a sustainable and economic selection of part candidates for additive manufacturing”, Rapid Prototyping Journal, Vol. 21 No. 2, pp. 216-227. https://doi.org/10.1016/j.cad.2015.04.001.

Mani, M., Witherell, P. and Jee, H. (2017), "Design Rules for Additive Manufacturing: A Categorization”, ASME International Design Engineering Technical Conferences and Computers and Information in Engineering Conference, Volume 1: 37th Computers and Information in Engineering Conference. https://doi.org/10.1115/DETC2017-68446.

Michopoulos, J.G., Steuben, J.C. and Iliopoulos, A.P. (2018), "Differential Performance Signature Qualification for Additively Manufactured Parts", ASME International Design Engineering Technical Conferences and Computers and Information in Engineering Conference, Volume 1A: 38th Computers and Information in Engineering Conference. https://doi.org/10.1115/DETC2018-85985.

Montero, J., Paetzold, K., Bleckmann, M. and Holtmannspoetter, J. (2018), "Re-Design and Re-Manufacturing of Discontinued Spare Parts Implementing Additive Manufacturing in the Military Field", Proceedings of the DESIGN 2018 15th International Design Conference, pp. 1269-1278. https://doi.org/10.21278/idc.2018.0444.

Panesar, A., Abdi, M., Hickman, D. and Ashcroft, I. (2018), "Strategies for functionally graded lattice structures derived using topology optimisation for additive manufacturing", Additive manufacturing, Vol. 19, pp. 8194. https://doi.org/10.1016/j.addma.2017.11.008.

Ranjan, R., Samant, R. and Anand, S. (2017), "Integration of design for manufacturing methods with topology optimization in additive manufacturing”, ASME Journal of Manufacturing Science and Engineering. Vol. 139 No. 6. https://doi.org/10.1115/1.4035216.

Robbins, J., Owen, S.J., Clark, B.W. and Voth, T.E. (2016), “An efficient and scalable approach for generating topologically optimized cellular structures for additive manufacturing", Additive Manufacturing, Vol. 12 No. Part B, pp. 296-304. https://doi.org/10.1016/j.addma.2016.06.013.

Saaty, T.L. (2008), "Decision making with the analytic hierarchy process", International Journal of Services Sciences, Vol. 1 No. 1, pp. 83-98.http://dx.doi.org/10.1504/IJSSCI.2008.017590.

Simpson, T.W. and Williams, M.H. (2017), "Preparing industry for additive manufacturing and its applications: Summary \& recommendations from National Science Foundation workshop", Additive Manufacturing, Vol. 13, pp 166-178. https://doi.org/10.1016/j.addma.2016.08.002.

Stanković, T., Mueller, J., Egan, P. and Shea, K. (2015), “A generalized optimality criteria method for optimization of additively manufactured multimaterial lattice structures", ASME Journal of Mechanical Design, Vol. 137. https://doi.org/10.1115/1.4030995.

Wohlers Associates, Inc. (2018), Wohlers Report 2018 3D Printing and Additive Manufacturing State of the Industry Annual Worldwide Progress Report, ISBN 978-0-9913332-4-0.

Zegard, T. and Paulino, G.H. (2016), "Bridging topology optimization and additive manufacturing", Structural and Multidisciplinary Optimization, Vol. 53 No. 1, pp. 175-192. https://doi.org/10.1007/s00158-0151274-4.

\section{ACKNOWLEDGMENTS}

Engineering company Enmac Ltd in Finland has made this research possible with their profound knowledge of design for AM. We thank Enmac Ltd for their professional support and their certain customers for kindly allowing publishing case study details. 